\title{
Management of multiple sclerosis in adolescents - current treatment options and related adherence issues
}

This article was published in the following Dove Press journal:

Adolescent Health, Medicine and Therapeutics

15 June 2010

Number of times this article has been viewed

\author{
Jean K Mah' \\ Jennifer E Thannhauser ${ }^{2}$ \\ 'Division of Neurology, Department \\ of Pediatrics, Faculty of Medicine, \\ University of Calgary, Calgary, \\ Alberta, Canada; ${ }^{2}$ Division of Applied \\ Psychology, Faculty of Education, \\ University of Calgary, Calgary, Alberta, \\ Canada
}

\begin{abstract}
Multiple sclerosis (MS) is a progressive inflammatory demyelinating disorder of the central nervous system that is increasingly recognized in children and adolescents. This realization comes with additional concerns about existing therapeutic options and the impact of the disease on health-related outcomes of adolescents with MS. This five-part review provides an update on management strategies relevant to the pediatric MS population. The first section gives an overview on the epidemiology and natural history of early onset MS. The second section outlines currently available MS treatments, including medications during acute relapses and long-term immunomodulatory therapies. The third section highlights adherence issues pertaining to MS, including the challenges uniquely faced by adolescents. The fourth section provides a summary of research into quality of life and psychosocial consequences of pediatric onset MS. Attention is drawn to the grief experience of affected adolescents and the importance of peer relationships. Finally, the family resilience framework is presented as a conceptual model to facilitate optimal adaptation of adolescents with MS. Healthcare professionals can promote resilience and treatment adherence by ensuring that these individuals and their families are sufficiently informed about available MS treatments, providing instrumental support for managing potential medication side effects, and addressing age-appropriate developmental needs.
\end{abstract}

Keywords: multiple sclerosis, disease-modifying therapies, adolescents, treatment adherence

\section{Introduction}

MS is an acquired immune-mediated disorder of the central nervous system that results in demyelination and axonal injury. The precise etiology is unknown. Under the influence of adhesion molecules, matrix metalloproteinases, and proinflammatory cytokines, auto-reactive T-cells invade the central nervous system and produce characteristic perivenular inflammatory MS lesions. ${ }^{1}$ Many genetic and environmental factors including exposure to passive smoking, Epstein-Barr virus, and suboptimal vitamin D status likely play important roles in the pathogenesis. ${ }^{2-4}$ Although MS affects primarily young adults between the ages of 20 to 40 years, it can also present during childhood and adolescence. The incidence of pediatric onset MS from one study in Germany was 0.3 per 100,000. ${ }^{5}$ In a longitudinal study of Canadian children under 18 years of age, the incidence of first acute demyelinating syndromes including optic neuritis, acute disseminated encephalomyelitis, transverse myelitis, and neuromyelitis optica was 0.9 per $100,000 .{ }^{6}$ Differences in the case definition for acute disseminated encephalomyelitis or MS, geographical location, and duration of follow-up likely accounted for much of the variation in the reported rates of early onset MS. The prevalence of pediatric MS from prospective studies was approximately $5 \%$ (2.2\% to $4.4 \%)$ of all MS cases. ${ }^{7-10}$
Correspondence: Jean K Mah

Alberta Children's Hospital, 2888

Shaganappi Trail N.W., Calgary, Alberta,

Canada T3B 6A8

Tel +l 4039552296

Fax +l 4039552922

Email jean.mah@albertahealthservices.ca 
Other retrospective series suggested that up to $10 \%$ of patients had onset of MS before 18 years of age. ${ }^{11,12}$ The majority of pediatric MS occurred during adolescence (see Table 1).

\section{Natural history and management issues in adolescent multiple sclerosis}

According to the International Pediatric MS Study Group (IPMSSG) consensus definitions, the diagnosis of pediatric MS can be made after two distinct clinical episodes of central nervous system demyelination separated by at least 30 days, after excluding other conditions such as infection, vasculitis, genetic disorders, metabolic diseases, or malignancy. ${ }^{2,13}$ Currently acute disseminated encephalomyelitis (ADEM) is not included as an initial demyelinating event for the diagnosis of pediatric MS, nor can it be used to determine dissemination in time or space. The presence of encephalopathy, defined by the IPMSSG as an acute change in the level of consciousness or behavior, distinguishes ADEM from other polysymptomatic clinically isolated demyelinating syndromes. ${ }^{13}$ Individuals who present with ADEM will require two non-ADEM episodes before being considered as having MS; up to $28 \%$ of children with initial ADEM-like events may develop MS. ${ }^{14}$

In the absence of a second clinical demyelinating event, brain magnetic resonance imaging (MRI) is helpful for confirming the diagnosis of MS. The presence of new
T2-hyperintense or gadolinium-enhanced brain MRI lesions at least three months after the initial clinical event serves to fulfill the criteria for dissemination in time. The revised McDonald criteria for dissemination in space include three of the following: a) nine or more white matter lesions or one gadolinium-enhancing lesion, b) three or more periventricular lesions, c) one or more juxtacortical lesion, and d) one or more infratentorial lesion. ${ }^{15}$ However, these adult criteria may not be sensitive enough for pediatric MS. ${ }^{16}$ A proposed modification for pediatric MS included at least two of the following: five or more lesions, two or more periventricular lesions, or at least one or more brainstem lesion; however, further validation is required. ${ }^{17,18}$ Other diagnostic tests include cerebrospinal fluid (CSF) analysis, aquaporin-4 IgG antibody for neuromyelitis optica, visual evoked potentials, and optical coherence tomography. ${ }^{19,20}$ The presence of CSF oligoclonal bands (or an elevated IgG index) plus two or more MRI lesions can also serve to fulfill the dissemination in space criteria for MS. ${ }^{15}$

Most individuals with pediatric MS present initially with a relapsing and remitting course; permanent disability can occur due to incomplete recovery during a relapse. Common presenting features during an acute demyelinating event in pediatric MS include gait ataxia, sensory complaints, motor weakness, visual loss, and/or brainstem dysfunction. ${ }^{19,21}$ The female to male ratio of pediatric MS increases with age, from 0.8 under age 6 years, to 1.6 between 6 to 10 years, and

Table I Prevalence of pediatric onset multiple sclerosis from selected studies

\begin{tabular}{|c|c|c|c|c|c|}
\hline $\begin{array}{l}\text { Study year and } \\
\text { location }\end{array}$ & Total & $\begin{array}{l}\text { Number (\%) of } \\
\text { early-onset cases }\end{array}$ & $\begin{array}{l}\text { Subgroup (\%) with age } \\
\text { range in years at onset } \\
\text { of symptoms }\end{array}$ & $\begin{array}{l}\text { Female to } \\
\text { male ratio }\end{array}$ & $\begin{array}{l}\text { Number (\%) and } \\
\text { types of multiple } \\
\text { sclerosis }\end{array}$ \\
\hline $\begin{array}{l}\text { Duquette et al } 1987, \\
\text { Canada"I }\end{array}$ & 4,632 & $125(2.7 \%)$ & $\begin{array}{l}8(6 \%) \leq 10 \mathrm{yrs} \\
117(94 \%) 11-16 \mathrm{yrs}\end{array}$ & 3.0 & $\begin{array}{l}70(56 \%) \text { RRMS } \\
27(22 \%) \text { PPMS } \\
27(22 \%) \text { RPMS }\end{array}$ \\
\hline $\begin{array}{l}\text { Ghezzi et al } 1997, \\
\text { Italy }^{7}\end{array}$ & 3,375 & 149 (4.4\%) & $\begin{array}{l}40(27 \%)<13 \mathrm{yrs} \\
109(73 \%) 13-16 \mathrm{yrs}\end{array}$ & 2.2 & $\begin{array}{l}97(65 \%) \text { RRMS } \\
44(30 \%) \text { RPMS } \\
8(5 \%) \text { PPMS }\end{array}$ \\
\hline $\begin{array}{l}\text { Boiko et al 2002, } \\
\text { Canada }^{8}\end{array}$ & 3,223 & $129(3.6 \%)$ & $\begin{array}{l}12(20 \%) \leq 10 \mathrm{yrs} \\
104(80 \%) 11-16 \mathrm{yrs}\end{array}$ & 2.9 & $\begin{array}{l}\text { II } 3(97 \%) \text { RRMS } \\
3(3 \%) \text { PPMS }\end{array}$ \\
\hline $\begin{array}{l}\text { Simone et al 2002, } \\
\text { Italy }^{12}\end{array}$ & 793 & $83(10.4 \%)$ & $\begin{array}{l}13(16 \%) \leq 10 \mathrm{yrs} \\
26(31 \%) 11-13 \mathrm{yrs} \\
44(53 \%) 14-16 \mathrm{yrs}\end{array}$ & 1.9 & $83(100 \%)$ RRMS \\
\hline $\begin{array}{l}\text { Renoux et al 2007, } \\
\text { France and Belgium } 9\end{array}$ & 17,934 & $394(2.2 \%)$ & $\begin{array}{l}30(8 \%) \leq 10 \mathrm{yrs} \\
7|(18 \%)| 1-12 \mathrm{yrs} \\
159(40 \%) 13-14 \mathrm{yrs} \\
34(34 \%) 15-17 \mathrm{yrs}\end{array}$ & 2.8 & $\begin{array}{l}385(98 \%) \text { RRMS } \\
9(2 \%) \text { PPMS }\end{array}$ \\
\hline $\begin{array}{l}\text { Chitnis et al } 2009 \text {, } \\
\text { United States }{ }^{10}\end{array}$ & 4,399 & 135 (3.1\%) & $\begin{array}{l}3(2 \%) \leq 10 \mathrm{yrs} \\
14(10 \%) \mid 1-12 \mathrm{yrs} \\
118(88 \%) \quad 13-17 \mathrm{yrs}\end{array}$ & 3.2 & $\begin{array}{l}\text { I } 32(98 \%) \text { RRMS } \\
3(2 \%) \text { PPMS }\end{array}$ \\
\hline
\end{tabular}

Abbreviations: RRMS, relapsing-remitting multiple sclerosis; PPMS, primary progressive multiple sclerosis; RPMS, relapsing progressive multiple sclerosis. 
2.1 for children over 10 years. ${ }^{2}$ There is a greater diversity in self-reported ethnicity and race among pediatric MS cases in North America. ${ }^{10,22}$

In contrast to adult MS, adolescents may experience more relapses initially, but they are more likely to recover from the neurological deficits. According to Gorman et al the annualized relapse rate was significantly higher in pediatric (up to three times greater) than in adult onset relapsing-remitting multiple sclerosis (RRMS). ${ }^{23}$ Children and adolescents with MS were also found to have a greater MRI disease burden suggestive of a highly inflammatory process in the early onset group. ${ }^{24}$ Paradoxically, despite early aggressive disease, disability is slower to accrue in pediatric MS, as adolescents may be less vulnerable to brain insults. ${ }^{25}$ Over time, however, a significant proportion of individuals with early onset MS will develop secondary progressive MS, which is associated with increasing physical disability in the absence of clinical relapses. ${ }^{8}{ }^{812}$ Renoux et al studied a cohort of 394 patients with onset of MS at or before 16 years of age from the 1976 to 2003 European Database for Multiple Sclerosis (EDMUS). ${ }^{9}$ Approximately half $(231,59 \%)$ had received one or more disease-modifying treatments during a follow-up period of 17.1 (standard deviation, SD, 13.2) years. 110 (29\%) converted to secondary progression at a median time interval of 28.1 (95\% confidence interval, CI, 25.0 to 32.1) years from the onset of pediatric MS, around a median age of 41.4 (CI, 37.8 to 45.7 ) years. Compared to 1,775 patients with onset after 16 years of age and followed without treatment until 1997, pediatric onset MS patients took 10 years longer to reach secondary progression and irreversible disability, but they were 10 years younger when they reached these landmarks. ${ }^{9}$ The presence of sphincter symptoms at onset, incomplete recovery from the first attack, and a short interval between the first and second attacks were found to be the strongest predictors of long-term physical disability in adults with RRMS. ${ }^{26}$ The impact of disease-modifying treatments as well as the identification of reliable predictors for significant disability in pediatric onset MS will require further longitudinal studies.

In addition to the progressive nature of the disease, the management of adolescents with MS can be challenging due to several key reasons. Firstly, as pediatric onset MS is relatively uncommon, the diagnosis can be delayed due to under-recognition by clinicians. ${ }^{27}$ Secondly, MS diseasemodifying treatments have not been formally approved for pediatric use due to a lack of double-blinded randomized clinical trials in this age group, and long-term safety data is not available. Thirdly, current disease-modifying treatments are only partially efficacious in reducing subsequent relapses and delaying the onset of permanent disability. Lastly, beyond the physical disability, adolescents with MS are at an increased risk for cognitive impairment and adverse psychological outcome.

Among 37 teens with MS, MacAllister et al found that 22 (59\%) had impairment on one or more tasks affecting their academic functioning, including difficulties with complex attention $(11 / 37,30 \%)$, naming $(7 / 37,19 \%)$, and receptive language $(5 / 37,4 \%){ }^{28}$ Thirteen (35\%) had significant cognitive impairment, with poor performance on at least two tasks. Cognitive impairment for study participants was positively correlated with current Expanded Disability Status Scale (EDSS), number of relapses, and duration of disease. Six out of eight participants had further cognitive decline at one-year follow-up. ${ }^{28}$ Similarly, in a smaller study of ten children with MS, significant neuropsychological deficits on several cognitive domains were identified, but there was no correlation between impairment and EDSS scores. ${ }^{29}$

More recently, Amato et al reported that 19 out of 63 (31\%) pediatric MS patients had major cognitive impairment (failed $\geq 3$ tests) while 32 (53\%) were mildly impaired (failed $\geq 2$ tests), due to deficits in memory, complex attention, executive function, and linguistic abilities. ${ }^{30}$ Seventeen (28\%) patients had an intelligent quotient (IQ) score below 90 , including five (8\%) with an IQ score less than 70; low IQ was significantly associated with younger age at onset. Remarkably, cognitive defects were detected even in subjects with low level of physical disability.

\section{Overview of treatment options}

As reviewed by Pohl et al current medical management for pediatric MS includes treatment during acute relapses to hasten recovery from significant neurological impairment, and long-term immunomodulatory therapies to reduce the frequency of clinical relapses and to slow the progression of disability (see Table 2). ${ }^{31}$ Treatments during acute relapses were largely based on anecdotal reports, and included high dose corticosteroids such as intravenous or oral methylprednisolone. ${ }^{32}$ Plasma exchange ${ }^{33,34}$ or intravenous immunoglobulin ${ }^{35,36}$ can serve as alternatives in case of suboptimal response to corticosteroids.

Long-term immunomodulatory therapies are currently only approved for adult onset MS. Pediatric experience with MS therapies are either derived from retrospective or prospective cohort studies; there are no long-term safety data for pediatric MS. Immunomodulatory therapies for adolescents included intramuscular interferon beta- $1 \mathrm{a},{ }^{37-40}$ 
Table 2 Current disease-modifying therapies for pediatric multiple sclerosis

\begin{tabular}{|c|c|c|c|c|}
\hline Drug & Dose & Route & Frequency & Potential side effects \\
\hline \multicolumn{5}{|l|}{ Acute relapses } \\
\hline Methylprednisolone ${ }^{32}$ & $20-30 \mathrm{mg} / \mathrm{kg}$, up to I gm & IV & Daily for $3-5$ days & $\begin{array}{l}\text { Growth retardation, } \\
\text { mood change, psychosis, } \\
\text { hypertension, hyperglycemia, } \\
\text { gastric irritation, avascular } \\
\text { necrosis }\end{array}$ \\
\hline Plasma exchange $\mathrm{e}^{33,34}$ & Double-volume exchange & IV & 5-7 exchanges & $\begin{array}{l}\text { Central venous line infection } \\
\text { or thrombosis, bleeding, } \\
\text { hypocalcemia, metabolic } \\
\text { acidosis }\end{array}$ \\
\hline $\begin{array}{l}\text { Intravenous } \\
\text { immunoglobulin } 35,36\end{array}$ & $0.4 \mathrm{mg} / \mathrm{kg}$ daily $\times 5$ days & IV & $\begin{array}{l}\mathrm{I} \mathrm{gm} / \mathrm{kg} \times 2 \text { days } \\
\text { every } 2-3 \text { months }\end{array}$ & $\begin{array}{l}\text { Systemic/allergic reaction, } \\
\text { headache, aseptic meningitis, } \\
\text { venous thrombosis }\end{array}$ \\
\hline \multicolumn{5}{|l|}{ Ist line therapies } \\
\hline Interferon beta- I $\mathrm{a}^{37-40}$ & $30 \mu \mathrm{g}$ & IM & Weekly & $\begin{array}{l}\text { Injection site reactions, } \\
\text { flu-like illness, elevated liver } \\
\text { enzymes }\end{array}$ \\
\hline Interferon beta-I $\mathrm{a}^{4 \mid-42}$ & 22 or $44 \mu \mathrm{g}$ & SC & 3 times a week & $\begin{array}{l}\text { Injection site reactions, } \\
\text { flu-like illness, elevated } \\
\text { liver enzymes, depression, } \\
\text { systemic reactions }\end{array}$ \\
\hline Interferon beta- $\mid b^{43}$ & $250 \mu \mathrm{g}(8 \mathrm{MIU})$ & SC & Every other day & $\begin{array}{l}\text { Injection site reactions, } \\
\text { flu-like illness, elevated liver } \\
\text { enzymes, systemic reactions }\end{array}$ \\
\hline Glatiramer acetate $\mathrm{e}^{44,45}$ & $20 \mathrm{mg}$ & SC & Daily & $\begin{array}{l}\text { Injection site reactions, } \\
\text { transient systemic reaction }\end{array}$ \\
\hline Azathioprine ${ }^{51}$ & $2.5-3 \mathrm{mg} / \mathrm{kg}$ & Oral & Daily & $\begin{array}{l}\text { Nausea, vomiting, } \\
\text { pancytopenia, elevated liver } \\
\text { enzymes, pancreatitis, risk of } \\
\text { malignancy }\end{array}$ \\
\hline \multicolumn{5}{|l|}{ 2nd line therapies } \\
\hline Cyclophosphamide ${ }^{52}$ & $\begin{array}{l}700-800 \mathrm{mg} / \mathrm{m}^{2} \text { titrated by } \\
\text { WBC, up to } 80 \text { gram total }\end{array}$ & IV & $\begin{array}{l}\text { Induction and/or } \\
\text { monthly }\end{array}$ & $\begin{array}{l}\text { Bone marrow suppression, } \\
\text { hemorrhagic cystitis, } \\
\text { alopecia, infection, infertility, } \\
\text { bladder cancer and other } \\
\text { malignancies }\end{array}$ \\
\hline Mitoxantrone $\mathrm{e}^{50}$ & $\begin{array}{l}12 \mathrm{mg} / \mathrm{m}^{2} \text {, up to } \\
120 \mathrm{mg} / \mathrm{m}^{2} \text { total }\end{array}$ & IV & Every 3 months & $\begin{array}{l}\text { Cardiotoxicity, infection, } \\
\text { bone marrow depression, } \\
\text { early menopause, risk of } \\
\text { leukemia }\end{array}$ \\
\hline Natalizumab ${ }^{54,55}$ & $3-5 \mathrm{mg} / \mathrm{kg}$, up to $300 \mathrm{mg}$ & IV & Monthly & $\begin{array}{l}\text { Infection, hypersensitivity } \\
\text { reaction, progressive } \\
\text { multifocal } \\
\text { leukoencephalopathy }\end{array}$ \\
\hline Methotrexate ${ }^{49}$ & $7.5 \mathrm{mg}$ & Oral & Weekly & $\begin{array}{l}\text { Anemia, pancytopenia, } \\
\text { infection, liver toxicity, } \\
\text { gastrointestional irritation }\end{array}$ \\
\hline
\end{tabular}

Abbreviations: IV, intravenous injection; IM, intramuscular injection; SC, subcutaneous injection.

subcutaneous interferon beta-1a, ${ }^{41,42}$ subcutaneous interferon beta- $1 \mathrm{~b},{ }^{43}$ and subcutaneous glatiramer acetate. ${ }^{44,45}$ A summary of pediatric experience with MS immunomodulatory therapies is provided in Table 3. Overall, these case series suggest that interferon beta (INFB) and glatiramer acetate are safe and well-tolerated, and may contribute to a reduction in relapse rates, MRI activity, or stabilization of disability scores in adolescents with MS. Side effects of immunomodulatory therapies are generally similar for pediatrics as well as adults. The choice of MS disease-modifying therapies will depend on individual patient and family's preference, after careful consideration of the potential benefits as well as side effects. The availability of immunomodulatory therapies may also vary depending on insurance coverage and financial support 


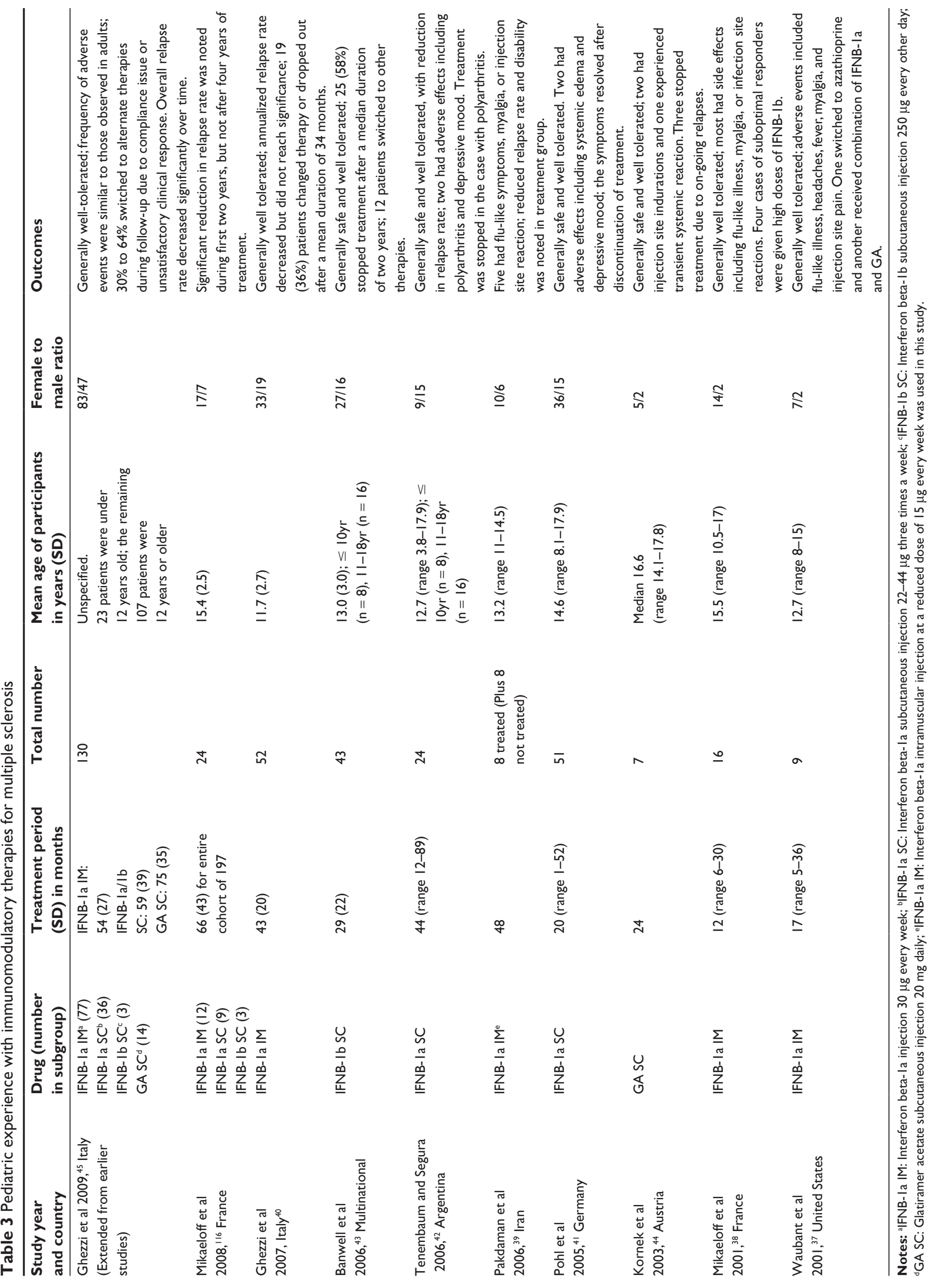


from regional health authorities. Adolescents should be counseled regarding effective contraceptives before initiating treatment due to potential teratogenicity.

The benefits of INFB may be mediated via a number of immunomodulatory mechanisms, including inhibition of autoreactive T-cells and proinflammatory cytokines ${ }^{46}$ On the other hand, INFB can produce flu-like symptoms, injection site reactions, pancytopenia, and elevation in liver enzymes that necessitates periodic laboratory monitoring. Serious adverse events including depression and systemic reactions such as polyarthritis or generalized edema were rare. ${ }^{31,42}$ Dosage reduction for INFB may be required for underweight or small for age adolescents to minimize drug-related toxicity. ${ }^{5}$ Glatiramer acetate (GA) is a synthetic molecule that resembles myelin basic protein, with anti-inflammatory and neuroprotective effects. ${ }^{47}$ It can cause injection site reactions and transient systemic reactions such as facial flushing, palpitations, tachycardia, and chest tightness. GA can be given without dosage adjustment in adolescents.

Definition of treatment failure varies among studies, but it is generally considered when any of the following events occur after being on MS disease-modifying therapies for at least six months: greater than one relapse per year, no decrease in relapse rate from baseline, incomplete recovery from relapses and/or accumulation of disability, new lesions on brain MRI, progressive multifocal disease, and worsening motor or cognitive impairment. ${ }^{48}$ Approximately one-quarter of individuals with pediatric onset MS will experience breakthrough disease necessitating a change to an alternate therapy after being on a first-line treatment for a mean duration of 18 months. ${ }^{19}$ Chemotherapeutic agents such as methotrexate and azathioprine have been used primarily in adults with MS as second-line therapies, with no long-term pediatric safety or efficacy data. ${ }^{49-51}$ Intravenous cyclophosphamide was given in specialized centers to pediatric MS patients who failed to respond to IFNB or GA. ${ }^{52}$ There are currently no longitudinal studies on mitoxantrone for refractory pediatric relapsing-remitting MS. Similarly, natalizumab is restricted as a second-line agent for adults due to risk of life-threatening infections such as progressive multifocal leukoencephalopathy or autoimmune complications. ${ }^{53}$ Pediatric experience with natalizumab in worsening relapsing-remitting MS is limited to two case reports..$^{54,55}$ There is no consensus on effective treatment for primary or secondary progressive MS in adolescents. ${ }^{56}$

In addition to treatment for acute relapses and long-term immunomodulatory therapies, adolescents with MS may benefit from comprehensive neurorehabilitation. Neuroreha- bilitation is an active process of education and enablement to help disabled individuals to realize their optimal physical, mental, and social potentials. ${ }^{57}$ There is currently no published clinical trials regarding the effectiveness of neurorehabilitation in pediatric MS; evidence-based research in adults is partly limited by trial design challenges and the nonuniform progression of disease among study participants. ${ }^{58}$ Nonetheless, there is evidence to support the short-term benefits of exercise program and/or in-patient neurorehabilitation for adults with progressive MS or moderate disability after a relapse. ${ }^{58,59}$ Similar to the self-management approach for adult MS, adolescents should be encouraged to pace themselves to avoid excessive fatigue, to adapt a well-balanced lifestyle including good nutrition, regular physical exercise, and rest, to redefine their developmental goals within the constraints of their illness, and to maintain important supportive relationships despite the many disruptions due to MS. Symptomatic therapy for spasticity, fatigue, tremor, bladder dysfunction, and depression should be offered when clinical indicated. . $^{31,60}$

Management of psychological distress and cognitive dysfunction for pediatric MS remains understudied, and the effectiveness of current psychotherapeutic approaches often goes undocumented. MacAllister et al recently provided several recommendations for psychological assessment and intervention, including individual and family therapies to address behavioral, social, emotional, and psychological issues that impact adolescent adjustment to the disease.${ }^{61}$ Supportive services such as summer camps and pen pal program provide opportunities for adolescents with MS to connect with each other. Finally, cognitive deficits may be addressed in conjunction with the schools through individualized educational strategies such as reduced workload, extended time limits, occupational therapy, and assistive technologies may enable the adolescents to participate in school and enhance their overall health-related quality of life.

Currently it is estimated that up to $80 \%$ of adults with MS use complementary and alternative medicine (CAM) at some point during their illness. ${ }^{62} \mathrm{CAM}$ refers to a broad domain of healing practices that are outside of conventional biomedicine. ${ }^{63}$ Although the incidence of CAM use among adolescents with MS is presently unknown, we have found a high rate (44\%) of CAM use in a cross-sectional survey among children and youth attending our pediatric neurology clinics. ${ }^{64}$ Potentially promising complementary therapies for MS include supplementation with essential fatty acids and/or vitamins, as well as the use of cannabis and yoga for symptomatic disease management. ${ }^{65,66} \mathrm{~A}$ recent 
randomized study involving 31 adults with RRMS found that fish oil supplementation in combination with a diet low in saturated fats was associated with short-term reduction in relapse rate and improved quality of life. ${ }^{67}$ There are currently no objective benefits in regards to vitamin $\mathrm{C}$, $\mathrm{E}$, or B12 supplementation. ${ }^{68,69}$ Besides being an environmental factor that mediates the prevalence of autoimmune diseases, vitamin D appears to confer a protective effect on the risk of developing MS, and randomized controlled trials using high dose vitamin $\mathrm{D}$ are in progress. ${ }^{70}$ Cannabis may be helpful for the management of spasticity and bladder symptoms in adults with MS, particularly if they fail to respond to conventional medications. ${ }^{69,71,72}$ Finally, yoga appears to be as effective as conventional exercise in improving fatigue among individuals with MS. ${ }^{73,74}$ Long-term data on safety and efficacy of these and other CAM are lacking. Further studies are required before they can be considered for pediatric MS. Until more data is available, patients should be advised regarding the potential limitations of CAM and the need to remain on conventional MS therapies.

\section{Adherence issues in adolescents related to treatment}

The unpredictable nature of MS creates an on-going sense of uncertainty that may affect adolescents' adherence to treatment. Adherence involves patient acceptance and followthrough with treatment plans $;^{75}$ adherence is preferred over compliance as it is more empowering to the patient. ${ }^{76}$ Patient adherence to treatment recommendations is influenced by a variety of factors including medical, demographic, developmental, cognitive-emotional, motivational, family support, peer support, and quality of interaction with healthcare providers. ${ }^{77}$ One major issue related to currently published adherence data is the lack of consistency in how adherence is defined. Nonadherence may be conceptualized as: a) a complete refusal of treatment, b) a refusal of specific treatment options, or c) an unintended or arbitrary modification to prescription. ${ }^{78}$ Even more likely is partial nonadherence, such as when patients forget or feel too tired to take a dose.

Adherence data specific to the pediatric MS population is limited. However, the adult population data can provide some insights into treatment adherence issues related to MS. Adult-based studies have reported adherence rates of $36 \%$ to $83 \%$. ${ }^{79-81}$ Common reasons for nonadherence included simply forgetting to administer medication, side effects such as injection-site reactions, needlephobia, difficulties with selfinjection technique, cost of treatment, cognitive impairment, depression, negative impact on quality of life, unrealistic expectations of treatment efficacy, treatment fatigue, and loss of confidence in therapeutic efficacy during relapse. ${ }^{79-83}$ Factors that were correlated with higher rates of adherence in adult MS patients include older age at disease onset and disease duration less than three years, whereas attempt at more than one disease-modifying therapy contributed to decreased adherence. ${ }^{81}$ Furthermore, adults who experience higher self-efficacy and increased hope are more likely to adhere to treatment recommendations. ${ }^{84}$

Treatment adherence for other adolescent chronic illnesses varies considerably. Overall, Kyngas reported that approximately half of adolescents with chronic diseases did not adhere to their treatment regimes. ${ }^{85}$ Among 266 adolescents (age 13-17 years) with asthma, Kyngas reported that $42 \%$ were fully adherent, $42 \%$ were partially adherent, and $18 \%$ had poor adherence. ${ }^{86}$ Similarly, for adolescents $(\mathrm{n}=289)$ with type 1 diabetes mellitus, complete adherence was identified only in $19 \%$ of the study participants, while $75 \%$ had partial adherence, and $6 \%$ had poor adherence. ${ }^{87}$ High nonadherence rates were also found in 232 adolescents with epilepsy, with $22 \%$ of them adhering fully, $44 \%$ adhering partially, and $34 \%$ adhering poorly. ${ }^{88}$ Among adolescents with asthma, epilepsy, diabetes, and juvenile rheumatoid arthritis, the best predictors for treatment adherence include motivation, willpower, fear of acute problems, concerns for their own emotional or social well being, and perceived support from parents, friends, or healthcare professionals. ${ }^{89,90}$

Most adolescents with MS require consistent administration to optimize the benefits of disease-modifying therapies. As well, there is an increasing body of evidence to support early initiation of immunomodulatory treatments for MS. ${ }^{91-93}$ Consequently, it is important to determine the extent to which adolescent patients are adhering to prescribed treatments. According to one report, compliance was high for this population when accompanied by extensive teaching. ${ }^{94}$ However, in another small pediatric MS cohort, eight (47\%) adolescents discontinued treatment after a median duration of 20 months..$^{95}$ Based on the available data, the cumulative adherence rate to MS disease-modifying therapies was $82 \%$ at year one, $75 \%$ at year two, 59\% at year three, 50\% at year four, and $38 \%$ at year five to eight. ${ }^{95}$ Consistent with another study, ${ }^{96}$ adolescent adherence appeared to decrease over time.

The unique developmental attributes during adolescence may contribute to low adherence rates. ${ }^{97,98}$ Adolescence is a critical developmental period marked by significant biological, psychological, and social change. Adolescents are transitioning from dependence to independence, adopting 
new emotional and social roles, and learning to adapt to new physiological changes. ${ }^{99}$ For the most part, this developmental period can be negotiated without major difficulties; however, some individuals run into barriers, such as having a chronic illness, and may not have adequate resources to overcome these challenges. Adolescents' sense of omnipotence, cognitive limitations in assessing risks and relative inexperience with long-term consequences (especially with an "invisible" disease like MS) may also lead to the belief that they do not need to follow the treatment plan. ${ }^{100,101}$ In addition, medical treatment can threaten the adolescents' desire for autonomy by creating a dependence on doctors and caregivers, which may cause the adolescents to reject their recommendations or assistance. ${ }^{102}$

The social systems within which these young patients live also influence their ability to adhere to treatment regimes. Specifically, peer relationships are of critical importance during adolescence. Treatment regimes can have negative implications for peer relationships, such as interrupting or restricting social activities and changing lifestyle. ${ }^{77}$ Injectionsite reactions and side effects of high dose corticosteroids can also alter physical appearance, resulting in adolescents becoming more self-conscious of their bodies. Feelings of being different can lead to social withdrawal. Pre-existing family dysfunction or other stressors may restrict much needed caregiver support and impede adolescents' followthrough with treatment regime. ${ }^{102}$

\section{Patient focused perspectives on quality of life and treatment acceptability}

Given that late childhood through adolescence is a critical time in social and emotional development, ${ }^{103}$ it is important for healthcare professionals to consider the impact of MS and its treatments on the long-term development of the pediatric patients. In order for adolescents with MS to maintain an acceptable quality of life, both their physical and psychosocial needs must be addressed. Currently there are conflicting reports in the literature as to the impact of chronic illness on adolescents' psychosocial development and health-related quality of life (HRQL). As a result of psychosocial development being defined in different ways, ${ }^{104,105}$ there is no consensus as to whether or not an adolescent with a chronic illness such as MS may experience adjustment difficulties.

As well, there is limited research exploring the impact of a diagnosis of MS on the lives of pediatric patients and their families. The treatment and care of adolescents with MS has been primarily modeled after the strategies developed for adults living with the disease. However, differences in developmental stages impact the applicability of these strategies. Adult-based studies have indicated decreased HRQL as a result of living with MS. ${ }^{106}$ Patients with higher levels of disability and/or cognitive impairment are more likely to experience limitations to physical functioning, general health, role limitation, vitality, and social functioning. ${ }^{107,108}$ Sensory, motor, and cognitive symptoms can interfere with activities of daily living. The use of immunomodulatory therapies may also have an effect on HRQL in MS, with variable results depending on the drug and the specific domain of quality of life assessed, though typically in a positive direction. ${ }^{106}$

A number of recent publications have described the potential psychosocial consequences of pediatric MS. ${ }^{109,61}$ Adolescents' dependence on long-term treatment, need for self-management, physical limitations, and unpredictability of the disease magnifies the differences between these youth and their peers, thus increasing the risk of loneliness. Uncertainty about the disease can also impede treatment adherence, especially if the individual is free of relapses for an extended period of time. Due to their current stage of cognitive development, the youth may have difficulty appreciating the importance of ongoing treatment. Further risk-taking behaviors and unhealthy lifestyle can negatively impact their HRQL. Several studies have identified the presence of depressive or anxious symptoms in pediatric MS patients, ranging from four $(6 \%)$ out of sixty-three patients with depression in one pediatric MS cohort ${ }^{30}$ to six out of thirteen adolescents (46\%) with major depression or anxiety disorders in another center. ${ }^{28}$ Depressive and anxious symptoms may be a consequence of the disease process or the adolescents' psychological reaction to the diagnosis. In the study by Amato et al parents also reported adverse behavioral changes in 16 (39\%) subjects, including increased anxiety, aggression, and isolation; in addition, the parents were more likely to perceive a greater degree of sleep and/or cognitive disturbance than the adolescents themselves. ${ }^{30}$ These studies collectively suggest that MS can result in negative psychological sequelae, especially if adequate support systems are not in place.

Overall, MacAllister et al found that the HRQL was significantly reduced in 51 (33 female, 18 male) pediatric onset MS patients; the majority were adolescents. ${ }^{110}$ They reported greater fatigue and difficulties with cognitive, physical, and academic performance compared to historical controls, with more than half experiencing at least mild degree of fatigue. Similarly, Amato et al found that fatigue was common $(46 / 63,73 \%)$ among their study participants. ${ }^{30}$ The majority 
(56\%) of them indicated that MS had a negative influence on school and everyday activities, including absences and reduced sport participation. With fatigue being an "invisible disability," the reluctance of teens to disclose symptoms might lead to an under-estimation of MS-related symptoms on their overall functioning. Having MS can greatly compromise adolescents' scholastic achievement, social engagement, and future career opportunities.

In an earlier study, Boyd and MacMillan recruited 12 children and adolescent MS patients from the Pediatric MS Clinic at the Hospital for Sick Children in Toronto, Canada. ${ }^{109}$ The researchers identified important social, psychological, and developmental experiences adversely affected by a diagnosis of pediatric MS. They noted that the participants shared common stressors such as unresolved symptoms, unpredictable relapses, missing school, demanding treatment regime, family conflicts, and an uncertain future. The participants' lives were changed, such that many had to modify their routines as a consequence of their disease and/or treatment. School difficulties due to cognitive challenges or school absenteeism were not uncommon. In addition, participants reported changes in peer relationships, both positively and negatively. Some relationships became stronger; other relationships grew distant. Shifts in identity as a consequence of living with MS were also evident in the same pediatric MS cohort. ${ }^{109}$ Participants described developing new appreciation of life after having lived with the disease over time. Even though the diagnosis of MS was accompanied by significant life-changing experiences, many aspects of the participants' lives remained the same.

In a recent qualitative study, Thannhauser presented the Peer-Grief Dynamic Theory as a preliminary theoretical model to describe the psychosocial experiences of adolescents with MS. ${ }^{111}$ Psychosocial development for participants occurred within the context of a grief process. As the adolescent with MS experienced losses related to their health or changes in their sense of normalcy, control, and relationships, they moved through a cyclic grief process. The adolescents vacillated back and forth between grief and acceptance with each loss experience. For some, movement from grief to acceptance became easier with each subsequent loss. Others, however, struggled with the challenge of repeatedly transitioning from grief to acceptance. Peer relationships were interrelated with the grief process as experienced by the adolescents with MS. ${ }^{111}$ The grief experience shaped the development of some peer relationships through the deepening of old relationships, creation of new relationships, or the loss of other friendships. However, peer relationships also affected the adolescent's progression through the grief experience by direct (eg, active support) and indirect (eg, loss of support due to adolescent withdrawing) means. Peers sometimes facilitated the movement through the grief experience and other times impeded the adolescents' ability to work through the grief. Providing adequate support to process grief is critical for reducing negative psychosocial sequelae of MS.

In a recent study on adolescent adherence to MS diseasemodifying therapy, ${ }^{95}$ the focus was placed on one category of data entitled "medication-peer tug-of-war" from Thannhauser's qualitative study. ${ }^{111}$ Struggles adolescents faced when attempting to integrate disease-modifying therapies into their daily routines provides a possible explanation for the relatively high nonadherence rate in this age group. The "medication-peer tug-of-war" was comprised of both an internal and an external conflict. The internal tug-of-war pertained to the adolescents' perception of treatment controlling important aspects of their lives, such as freedom to socialize. This internal tug-of-war also seemed to be tied to the loss of normalcy that many of the adolescents faced following their diagnosis. The loss of normalcy led to feelings of anger and worry, as many adolescents had to embrace changes that were beyond their control. However, one adolescent described a sense of security as long as she kept taking her medication regularly. Another adolescent was able to establish a new normal routine with daily instead of intermittent diseasemodifying treatment.

The external tug-of-war occurred between the adolescents and their social world. The peer group can act as a mediator between the participants' struggles with grief and acceptance of their disease. Negative reactions of peers to the injections, including peers being fearful of the injections, resulting in rejection and isolation, can amplify the experience of loss. Some adolescents withdrew from peers and social activities because of the fear they felt about doing their injections. Alternately, positive responses, including help with injections, interest in learning about the medications, and general emotional support, from peers and other key supportive figures in their lives helped the adolescents' transition towards acceptance of their disease.

\section{Discussion}

Because of the relapsing and remitting nature of MS, adolescents and their families may have difficulty adjusting to the fluctuations between attacks and the uncertainty of when the next relapse might recur. Concerns about disease recurrence can lead to parental hypervigilance and create 
further conflicts with the adolescents. The family resilience framework developed by Froma Walsh, co-founder and co-director of the Chicago Center of Family Health, can be applied to the pediatric MS population to serve as a guide to target and strengthen key processes that will encourage optimal adaptation of adolescents with MS. ${ }^{112}$ Resilience involves a dynamic process that enables individuals "to withstand and rebound from disruptive life challenges, becoming strengthened, and more resourceful." ${ }^{113}$ According to Walsh, the key processes in family resilience focus on: 1) beliefs system including making meaning of adversity, having a positive outlook, plus developing transcendence and spirituality, 2) organization pattern, by providing flexibility, connectedness, social and economic resources, and 3) communication strategy, with emphasis on clarity, open emotional expression, and collaborative problem-solving. ${ }^{112}$ Using Walsh's conceptual approach, clinicians may be in a better position to help adolescents and their families to gain insight about their illness experience, to appreciate the strengths and vulnerabilities of each family member and the emerging adolescent developmental needs, and to recognize key family beliefs that explain their illness narratives and relationships with healthcare professionals.

Clinicians can also foster the development of resilience through their direct interactions with the adolescents and their families. The discussion regarding the diagnosis and management of MS should take place with both the adolescent and parents present, and they should be encouraged to participate in all treatment decisions. The treating physician should provide written information about the illness and realistic expectations regarding potential benefits of disease-modifying therapies. Treatment side effects should be clearly explained along with appropriate management strategies. For example, co-medication acetaminophen or ibuprofen may help to minimize the flu-like symptoms of IFNB injections. Financial resources including funding for immunomodulatory therapies should be offered regardless of parental employment status or family income.

Parents should encourage their teenagers to meet ageappropriate developmental goals, including gradual transfer of decision-making authority over time. A resilience-oriented approach also draws upon extended family and peer resources as potential mentors and positive role models, as described in the previous section regarding the importance of supportive peer relationships in mediating adolescent adjustment to MS. Clinicians can help families resolve conflicts, identify coping strategies, develop realistic goals, and seek help when needed. Periodic family meetings and multidisciplinary consultations for anticipated transitions, including going away for college and/or transfer to adult services, can facilitate proactive planning and alleviate unnecessary anxiety.

From the adolescents' perspective, there is a need to restore normalcy in their day-to-day activities. The injections should be incorporated as part of their daily routine, with the least amount of intrusion as possible. Normalizing the psychosocial challenges such as injection phobia, fatigue, and learning difficulties as common and understandable can help them to avoid unnecessary self-blame, shame, or guilt. As well, encouraging the adolescents to take control of their treatment and to learn to inject themselves can enhance their self-esteem and promote a sense of mastery of their own lives. Adherence to MS disease-modifying therapies may be further improved by frequent follow-up via clinic visits or phone calls, being part of a peer support network, and having the options of more convenient, acceptable, and simplified forms of treatment. Emerging oral therapies for relapsing-remitting MS including teriflunomide, cladribine, fingolimod, laquinimod, and fumarate are currently in phase II/III clinical trials. ${ }^{114,115}$ Further studies regarding their safety, tolerability, and efficacy will be required before consideration as alternative treatments for MS.

\section{Conclusion}

Pediatric MS is a challenging chronic disease that requires multidisciplinary collaboration of healthcare professionals and individualized treatment approach for the adolescent patients and their families. Adherence can be problematic for many adolescents with MS, as the benefits of treatment are not observed immediately, and immunomodulatory therapies may be prescribed early in the disease when the youth are feeling quite healthy. To improve their treatment adherence, clinicians should ensure that these adolescents and their families understand the purpose of MS disease-modifying therapies, have appropriate expectations of treatment benefits, and can manage the potential adverse effects. Hopefully more tolerable medications with better side effects profile and ease of delivery will become available in the near future.

\section{Disclosure}

The authors report no conflicts of interest in this work.

\section{References}

1. Bar-Or A. The immunology of multiple sclerosis. Semin Neurol. 2008; 28(1):29-45.

2. Banwell B, Ghezzi A, Bar-Or A, Mikaeloff Y, Tardieu M. Multiple sclerosis in children: clinical diagnosis, therapeutic strategies, and future directions. Lancet Neurol. 2007;6(10):887-902. 
3. Ebers GC. Environmental factors and multiple sclerosis. Lancet Neurol. 2008;7(3):268-277.

4. Kulie T, Groff A, Redmer J, Hounshell J, Schrager S. Vitamin D: an evidence-based review. J Am Board Fam Med. 2009; 22(6): 698-706.

5. Pohl D. Epidemiology, immunopathogenesis, and management of pediatric central nervous system inflammatory demyelinating conditions. Curr Opin Neurol. 2008;21(3):366-372.

6. Banwell B, Kennedy J, Sadovnick D, et al. Incidence of acquired demyelination of the CNS in Canadian children. Neurology. 2009;72(3):232-239.

7. Ghezzi A, Deplano V, Faroni J, et al. Multiple sclerosis in childhood: clinical features of 149 cases. Mult Scler. 1997;3(1):43-46.

8. Boiko A, Vorobeychik G, Paty D, Devonshire V, Sadovnick D; University of British Columbia MS Clinic Neurologists. Early onset multiple sclerosis: a longitudinal study. Neurology. 2002;59(7): 1006-1010

9. Renoux C, Vukusic S, Mikaeloff Y, et al. Natural history of multiple sclerosis with childhood onset. $N$ Engl J Med. 2007;356(25): 2603-2613.

10. Chitnis T, Glanz B, Jaffin S, Healy B. Demographics of pediatric-onset multiple sclerosis in an MS center population from the Northeastern United States. Mult Scler. 2009;159(5):627-631.

11. Duquette P, Murray TJ, Pleines J, et al. Multiple sclerosis in childhood: clinical profile in 125 patients. J Pediatr. 1987;111(3):359-363.

12. Simone IL, Carrara D, Tortorella C, et al. Course and prognosis in early-onset MS: comparison with adult-onset forms. Neurology. 2002;59(12):1922-1928.

13. Krupp LB, Banwell B, Tenembaum S; International Pediatric MS Study Group. Consensus definitions proposed for pediatric multiple sclerosis and related disorders. Neurology. 2007;68(16 Suppl 2): S7-S12.

14. Tenembaum S, Chitnis T, Ness J, Hahn JS; International Pediatric MS Study Group. Acute disseminated encephalomyelitis. Neurology. 2007;68(16 Suppl 2):S23-S36.

15. Polman CH, Reingold SC, Edan G, et al. Diagnostic criteria for multiple sclerosis: 2005 revisions to the "McDonald Criteria". Ann Neurol. 2005;58(6):840-846.

16. Hahn CD, Shroff MM, Blaser SI, Banwell BL. MRI criteria for multiple sclerosis: evaluation in a pediatric cohort. Neurology. 2004;62(5):806-808.

17. Callen DJ, Shroff MM, Branson HM, et al. MRI in the diagnosis of pediatric multiple sclerosis. Neurology. 2009;72(11):961-967.

18. Callen DJ, Shroff MM, Branson HM, et al. Role of MRI in the differentiation of ADEM from MS in children. Neurology. 2009;72(11):968-973.

19. Yeh EA, Chitnis T, Krupp L, et al. Pediatric multiple sclerosis. Nat Rev Neurol. 2009;5(11):621-631.

20. Yeh EA, Weinstock-Guttman B, Lincoff N, et al. Retinal nerve fiber thickness in inflammatory demyelinating diseases of childhood onset. Mult Scler. 2009;15(7):802-810.

21. Ness JM, Chabas D, Sadovnick AD, et al. Clinical features of children and adolescents with multiple sclerosis. Neurology. 2007; 68(16 Suppl 2):S37-S45.

22. Kennedy J, O’Connor P, Sadovnick AD, Perara M, Yee I, Banwell B. Age at onset of multiple sclerosis may be influenced by place of residence during childhood rather than ancestry. Neuroepidemiology. 2006;26(3):162-167.

23. Gorman MP, Healy BC, Polgar-Turcsanyi M, Chitnis T. Increased relapse rate in pediatric-onset compared with adult-onset multiple sclerosis. Arch Neurol. 2009;66(1):54-59.

24. Yeh EA, Weinstock-Guttman B, Ramanathan M, et al. Magnetic resonance imaging characteristics of children and adults with paediatriconset multiple sclerosis. Brain. 2009;132(Pt 12):3392-3400.

25. Anderson V, Spencer-Smith M, Leventer R, et al. Childhood brain insult: can age at insult help us predict outcome? Brain. 2009;132 (Pt 1):45-56.
26. Langer-Gould A, Popat RA, Huang SM, et al. Clinical and demographic predictors of long-term disability in patients with relapsing-remitting multiple sclerosis: a systematic review. Arch Neurol. 2006;63(12):1686-1691.

27. Waldman A, O'Connor E, Tennekoon G. Childhood multiple sclerosis: a review. Ment Retard Dev Disabil Res Rev. 2006;12(2):147-156.

28. MacAllister WS, Belman AL, Milazzo M, et al. Cognitive functioning in children and adolescents with multiple sclerosis. Neurology. 2005;64(8):1422-1425.

29. Banwell BL, Anderson PE. The cognitive burden of multiple sclerosis in children. Neurology. 2005;64(5):891-894.

30. Amato MP, Goretti B, Ghezzi A, et al. Cognitive and psychosocial features of childhood and juvenile MS. Neurology. 2008;70(20): 1891-1897.

31. Pohl D, Waubant E, Banwell B, et al. Treatment of pediatric multiple sclerosis and variants. Neurology. 2007;68(16 Suppl 2):S54-S65.

32. Martinelli V, Rocca MA, Annovazzi P, et al. A short-term randomized MRI study of high-dose oral vs intravenous methylprednisolone in MS. Neurology. 2009;73(22):1842-1848.

33. Takahashi I, Sawaishi Y, Takeda O, Enoki M, Takada G. Childhood multiple sclerosis treated with plasmapheresis. Pediatr Neurol. 1997; 17(1):83-87.

34. Lehmann HC, Hartung HP, Hetzel GR, Stüve O, Kieseier BC. Plasma exchange in neuroimmunological disorders. Part 1: rationale and treatment of inflammatory central nervous system disorders. Arch Neurol. 2006;63(7):930-935.

35. Spalice A, Properzi E, Lo Faro V, Acampora B, Iannetti P. Intravenous immunoglobulin and interferon: successful treatment of optic neuritis in pediatric multiple sclerosis. J Child Neurol. 2004;19(8):623-626.

36. Dastgir J, DiMario FJ. Acute tumefactive demyelinating lesions in a pediatric patient with known diagnosis of multiple sclerosis: review of the literature and treatment proposal. J Child Neurol. 2009;24(4): 431-437.

37. Waubant E, Hietpas J, Stewart T, et al. Interferon beta-1a in children with multiple sclerosis is well tolerated. Neuropediatrics. 2001;32(4): 211-213.

38. Mikaeloff Y, Moreau T, Debouverie M, et al. Interferon-beta treatment in patients with childhood-onset multiple sclerosis. J Pediatr. 2001;139(3):443-446.

39. Pakdaman H, Fallah A, Sahraian MA, Pakdaman R, Meysamie A. Treatment of early onset multiple sclerosis with suboptimal dose of interferon beta-1a. Neuropediatrics. 2006;37(4):257-260.

40. Ghezzi A, Amato MP, Capobianco M, et al. Treatment of early-onset multiple sclerosis with intramuscular interferonbeta-1a: long-term results. Neurol Sci. 2007;28(3):127-132.

41. Pohl D, Rostasy K, Gärtner J, Hanefeld F. Treatment of early onset multiple sclerosis with subcutaneous interferon beta-1a. Neurology. 2005;64(5):888-890.

42. Tenembaum SN, Segura MJ. Interferon beta-1a treatment in childhood and juvenile-onset multiple sclerosis. Neurology. 2006;67(3): 511-513.

43. Banwell B, Reder AT, Krupp L, et al. Safety and tolerability of interferon beta-1b in pediatric multiple sclerosis. Neurology. 2006;66(4): $472-476$.

44. Kornek B, Bernert G, Balassy C, Geldner J, Prayer D, Feucht M. Glatiramer acetate treatment in patients with childhood and juvenile onset multiple sclerosis. Neuropediatrics. 2003;34(3):120-126.

45. Ghezzi A, Amato MP, Annovazzi P, et al. Long-term results of immunomodulatory treatment in children and adolescents with multiple sclerosis: the Italian experience. Neurol Sci. 2009;30(3):193-199.

46. Goodin DS. Treatment of multiple sclerosis with human beta interferon. Int MS J. 2005;12(3):96-108.

47. Tselis A, Khan O, Lisak RP. Glatiramer acetate in the treatment of multiple sclerosis. Neuropsychiatr Dis Treat. 2007;3(2):259-267.

48. Cohen BA, Khan O, Jeffery DR, et al. Identifying and treating patients with suboptimal responses. Neurology. 2004;63(12 Suppl 6): S33-S40. 
49. Gray OM, McDonnell GV, Forbes RB. A systematic review of oral methotrexate for multiple sclerosis. Mult Scler. 2006;12(4):507-510.

50. Neuhaus O, Kieseier BC, Hartung HP. Immunosuppressive agents in multiple sclerosis. Neurotherapeutics. 2007;4(4):654-660.

51. Casetta I, Iuliano G, Filippini G. Azathioprine for multiple sclerosis [discussion]. J Neurol Neurosurg Psychiatry. 2009;80(2):131-2.

52. Makhani N, Gorman MP, Branson HM, Stazzone L, Banwell BL, Chitnis T. Cyclophosphamide therapy in pediatric multiple sclerosis. Neurology. 2009;72(24):2076-2082.

53. Kleinschmidt-DeMasters BK, Tyler KL. Progressive multifocal leukoencephalopathy complicating treatment with natalizumab and interferon beta-1a for multiple sclerosis. $N$ Engl J Med. 2005;353(4):369-374.

54. Huppke P, Stark W, Zürcher C, Huppke B, Brück W, Gärtner J. Natalizumab use in pediatric multiple sclerosis. Arch Neurol. 2008;65(12): 1655-1658.

55. Borriello G, Prosperini L, Luchetti A, Pozzilli C. Natalizumab treatment in pediatric multiple sclerosis: a case report. Eur J Paediatr Neurol. 2009;13(1):67-71.

56. Wiendl H, Hohlfeld R. Multiple sclerosis therapeutics: unexpected outcomes clouding undisputed successes. Neurology. 2009;72(11): 1008-1015.

57. Kesselring J. Neurorehabilitation in multiple sclerosis - what is the evidence-base? J Neurol. 2004;251 Suppl 4:IV25-IV29.

58. Kesselring J, Beer S. Symptomatic therapy and neurorehabilitation in multiple sclerosis. Lancet Neurol. 2005;4(10):643-652.

59. Thompson AJ. Neurorehabilitation in multiple sclerosis: foundations, facts, and fiction. Curr Opin Neurol. 2005;18(3):267-271.

60. Goldman MD, Cohen JA, Fox RJ, Bethoux FA. Multiple sclerosis: treating symptoms, and other general medical issues. Cleve Clin J Med. 2006;73(2):177-186.

61. MacAllister WS, Boyd JR, Holland NJ, Milazzo MC, Krupp LB; International Pediatric MS Study Group. The psychosocial consequences of pediatric multiple sclerosis. Neurology. 2007;68(16 Suppl 2): S66-S69.

62. Apel-Neu A, Zettl UK. Complementary and alternative medicine in multiple sclerosis. J Neurol. 2008;255 Suppl 6:82-86.

63. Tataryn DJ. Paradigms of health and disease: a framework for classifying and understanding complementary and alternative medicine. J Altern Complement Med. 2002;8(6):877-892.

64. Soo I, Mah JK, Barlow K, Hamiwka L, Wirrell E. Use of complementary and alternative medical therapies in a pediatric neurology clinic. Can J Neurol Sci. 2005;32(4):524-528.

65 . Huntley A. A review of the evidence for efficacy of complementary and alternative medicines in MS. Int MS J. 2006;13(1):5-12.

66. Yadav V, Bourdette D. Complementary and alternative medicine: is there a role in multiple sclerosis? Curr Neurol Neurosci Rep. 2006;6(3):259-267.

67. Weinstock-Guttman B, Baier M, Park Y, et al. Low fat dietary intervention with omega-3 fatty acid supplementation in multiple sclerosis patients. Prostaglandins Leukot Essent Fatty Acids. 2005;73(5):397-404.

68. Zhang SM, Hernán MA, Olek MJ, Spiegelman D, Willett WC, Ascherio A. Intakes of carotenoids, vitamin C, and vitamin E and MS risk among two large cohorts of women. Neurology. 2001;57(1):75-80.

69. Wade DT, Makela P, Robson P, House H, Bateman C. Do cannabis-based medicinal extracts have general or specific effects on symptoms in multiple sclerosis? A double-blind, randomized, placebo-controlled study on 160 patients. Mult Scler. 2004; 10(4):434-441.

70. Munger KL, Zhang SM, O'Reilly E, et al. Vitamin D intake and incidence of multiple sclerosis. Neurology. 2004;62(1):60-65.

71. Vaney C, Heinzel-Gutenbrunner M, Jobin P, et al. Efficacy, safety and tolerability of an orally administered cannabis extract in the treatment of spasticity in patients with multiple sclerosis: a randomized, double-blind, placebo-controlled, crossover study. Mult Scler. 2004;10(4):417-424.
72. Brady CM, DasGupta R, Dalton C, Wiseman OJ, Berkley KJ, Fowler CJ. An open-label pilot study of cannabis-based extracts for bladder dysfunction in advanced multiple sclerosis. Mult Scler. 2004;10(4):425-433.

73. Shinto L, Yadav V, Morris C, Lapidus JA, Senders A, Bourdette D. The perceived benefit and satisfaction from conventional and complementary and alternative medicine (CAM) in people with multiple sclerosis. Complement Ther Med. 2005;13(4):264-272.

74. Oken BS, Kishiyama S, Zajdel D, et al. Randomized controlled trial of yoga and exercise in multiple sclerosis. Neurology. 2004;62(11): 2058-2064.

75. World Health Organization. Adherence to Long-term Therapies: Evidence for Action. Geneva: WHO; 2003.

76. Lugaresi A. Addressing the need for increased adherence to multiple sclerosis therapy: can delivery technology enhance patient motivation? Expert Opin Drug Deliv. 2009;6(9):995-1002.

77. Kyngas H, Duffy ME, Kroll T. Conceptual analysis of compliance. J Clin Nurs. 2000;9(1):5-12.

78. Klauer T, Zettl UK. Compliance, adherence, and the treatment of multiple sclerosis. J Neurol. 2008;255 Suppl 6:87-92.

79. Río J, Porcel J, Téllez N, et al. Factors related with treatment adherence to interferon beta and glatiramer acetate therapy in multiple sclerosis. Mult Scler. 2005;11(3):306-309.

80. Portaccio E, Zipoli V, Siracusa G, Sorbi S, Amato MP. Long-term adherence to interferon beta therapy in relapsing-remitting multiple sclerosis. Eur Neurol. 2008;59(3-4):131-135.

81. Treadaway K, Cutter G, Salter A, et al. Factors that influence adherence with disease-modifying therapy in MS. J Neurol. 2009;256(4): 568-576.

82. Clerico M, Barbero P, Contessa G, Ferrero C, Durelli L. Adherence to interferon-beta treatment and results of therapy switching. J Neurol Sci. 2007;259(1-2):104-108.

83. Cohen BA, Rieckmann P. Emerging oral therapies for multiple sclerosis. Int J Clin Pract. 2007;61(11):1922-1930.

84. Fraser C, Hadjimichael O, Vollmer T. Predictors of adherence to Copaxone therapy in individuals with relapsing-remitting multiple sclerosis. J Neurosci Nurs. 2001;33(5):231-239.

85. Kyngas HA, Kroll T, Duffy ME. Compliance in adolescents with chronic diseases: a review. J Adolesc Health. 2000;26(6):379-388.

86. Kyngas HA. Compliance of adolescents with asthma. Nurs Health Sci. 1999;1(3):195-202.

87. Kyngas HA. Predictors of good adherence of adolescents with diabetes (insulin-dependent diabetes mellitus). Chronic Illn. 2007;3(1):20-28.

88. Kyngas H. Compliance with health regimens of adolescents with epilepsy. Seizure. 2000;9(8):598-604.

89. Kyngas H. Predictors of good compliance in adolescents with epilepsy. Seizure. 2001;10(8):549-553.

90. Kyngas H. Motivation as a crucial predictor of good compliance in adolescents with rheumatoid arthritis. Int J Nurs Pract. 2002;8(6):336-341.

91. Ghezzi A; Immunomodulatory Treatment of Early Onset MS (ITEMS) Group. Immunomodulatory treatment of early onset multiple sclerosis: results of an Italian Co-operative Study. Neurol Sci. 2005; 26 Suppl 4:S183-S186.

92. Trojano M, Pellegrini F, Paolicelli D, et al. Real-life impact of early interferon beta therapy in relapsing multiple sclerosis. Ann Neurol. 2009;66(4):513-520.

93. Comi G, Martinelli V, Rodegher M, et al. Effect of glatiramer acetate on conversion to clinically definite multiple sclerosis in patients with clinically isolated syndrome (PreCISe study): a randomised, doubleblind, placebo-controlled trial. Lancet. 2009;374(9700):1503-1511.

94. Banwell BL. Pediatric multiple sclerosis. Curr Neurol Neurosci Rep. 2004;4(3):245-252.

95. Thannhauser JE, Mah JK, Metz LM. Adherence of adolescents to multiple sclerosis disease-modifying therapy. Pediatr Neurol. 2009;41(2):119-123. 
96. Smith BA, Shuchman M. Problem of nonadherence in chronically ill adolescents: strategies for assessment and intervention. Curr Opin Pediatr. 2005;17(5):613-618.

97. Rapoff MA. Management of adherence and chronic rheumatic disease in children and adolescents. Best Pract Res Clin Rheumatol. 2006;20(2):301-314.

98. Costello K, Kennedy P, Scanzillo J. Recognizing nonadherence in patients with multiple sclerosis and maintaining treatment adherence in the long term. Medscape J Med. 2008;10(9):225.

99. Brown RT, Boeving, LaRosa, A, Carpenter. Behavioral and Emotional Disorders in Adolescents: Nature, Assessment, and Treatment. New York: Guillford Press; 2006.

100. Brooks-Gunn, J. Developmental Aspects of Health Compliance Behavior. Hillsdale, NJ: Erlbaum; 1993.

101. Pritchard MT, Butow PN, Stevens MM, Duley JA. Understanding medication adherence in pediatric acute lymphoblastic leukemia: a review. J Pediatr Hematol Oncol. 2006;28(12):816-823.

102. Shaw RJ, Palmer L, Blasey C, Sarwal M. A typology of nonadherence in pediatric renal transplant recipients. Pediatr Transplant. 2003;7(6):489-493.

103. Erikson, EH. Identity: Youth and Crisis. New York: W. W. Norton and Company, Inc; 1985.

104. Cadman D, Boyle M, Szatmari P, Offord DR. Chronic illness, disability, and mental and social well-being: findings of the Ontario Child Health Study. Pediatrics. 1987;79(5):805-813.

105. Brown, RT, Marcias, M. Handbook of Psychological Services for Children and Adolescents. Oxford: Oxford University Press; 2001.

106. Rudick RA, Miller DM. Health-related quality of life in multiple sclerosis: current evidence, measurement and effects of disease severity and treatment. CNS Drugs. 2008;22(10):827-839.
107. Nortvedt MW, Riise T, Myhr KM, Nyland HI. Quality of life in multiple sclerosis: measuring the disease effects more broadly. Neurology. 1999;53(5):1098-1103.

108. Benito-León J, Morales JM, Rivera-Navarro J, Mitchell A. A review about the impact of multiple sclerosis on health-related quality of life. Disabil Rehabil. 2003;25(23):1291-1303.

109. Boyd JR, MacMillan LJ. Experiences of children and adolescents living with multiple sclerosis. J Neurosci Nurs. 2005;37(6):334-342.

110. MacAllister WS, Christodoulou C, Troxell R, et al. Fatigue and quality of life in pediatric multiple sclerosis. Mult Scler. 2009;15(12): 1502-1508.

111. Thannhauser JE. Grief-peer dynamics: understanding experiences with pediatric multiple sclerosis. Qual Health Res. 2009;19(6):766-777.

112. Walsh F. Family resilience: a framework for clinical practice. Fam Process. 2003;42(1):1-18.

113. Rolland JS, Walsh F. Facilitating family resilience with childhood illness and disability. Curr Opin Pediatr. 2006;18(5):527-538.

114. Warnke C, Meyer Zu Hörste G, Hartung HP, Stüve O, Kieseier BC. Review of teriflunomide and its potential in the treatment of multiple sclerosis. Neuropsychiatr Dis Treat. 2009;5:333-340.

115. Rammohan KW, Shoemaker J. Emerging multiple sclerosis oral therapies. Neurology. 2010;74 Suppl 1:S47-S53.

116. Mikaeloff Y, Caridade G, Tardieu M, Suissa S; KIDSEP study group of the French Neuropediatric Society. Effectiveness of early beta interferon on the first attack after confirmed multiple sclerosis: a comparative cohort study. Eur J Paediatr Neurol. 2008;12(3):205-209.
Adolescent Health, Medicine and Therapeutics

\section{Publish your work in this journal}

Adolescent Health, Medicine and Therapeutics is an international, peer-reviewed, open access journal focusing on health, pathology, and treatment issues specific to the adolescent age group. All aspects of health maintenance, preventative measures and disease treatmen interventions are addressed within the journal and practitioners from

\section{Dovepress}

all disciplines are invited to submit their work as well as healthcare researchers and patient support groups.. The manuscript management system is completely online and includes a very quick and fair peerreview system. Visit http://www.dovepress.com/testimonials.php to read real quotes from published authors. 